\title{
Effect of Mesopores of Marimo Nano Carbon Anode Material on Power Generation Performance of Direct Glucose Fuel Cell
}

\author{
Akiyama Shingo $^{\mathrm{a}}$ and Kiyoharu Nakagawa ${ }^{\mathrm{b}}$ \\ ${ }^{a}$ Department of Science and Engineering, Kansai University, 3-3-35, Yamate-cho, Suita, \\ Osaka, 564-8680, Japan, \\ ${ }^{\mathrm{b}}$ Kansai University and High Technology Research Core, 3-3-35, Yamate-cho, Suita, \\ Osaka, 564-8680, Japan, \\ E-mail: kiyoharu@kansai-u.ac.jp
}

\begin{abstract}
In this study, the effect of the mesopores of Marimo nano carbon (MNC) on power generation performance for anode material of direct glucose fuel cell was investigated. Three types of MNC with different mesopore distributions were used for the catalyst support material, Pt was used as loaded metal. In the glucose fuel cell performance test, MNC having many pores of about $35 \mathrm{~nm}$ showed the highest maximum output density of $0.72 \mathrm{~mW} \mathrm{~cm}^{-2}$ at $5 \mathrm{wt} \%$ metal loading and $0.3 \mathrm{M}$ Glucose aqueous solution. The pores of about $30 \mathrm{~nm}$ may promote ion diffusion and rapid mass transport of reactants and products. These results indicated that MNC was an effective material as anode material for direct glucose fuel cell.
\end{abstract}

\section{Introduction}

Direct Glucose Fuel Cell (DGFC) is attracting attention as a clean and sustainable energy source because glucose is the most organic substance in nature. Most of glucose fuel cells utilized microbial and enzymatic approaches to obtain energy from the glucose oxidation processes (1-4). However, the use of these glucose fuel cells for practical applications is limited because of the poor output performance and the low durability of microbial organisms and enzymes. To resolve their problems, DGFCs with various non-enzymatic catalysts have been proposed. Precious metal catalysts loaded on nano carbon materials show great glucose oxidation activity due to their high surface area and high electric conductivity $(5,6)$

Conventionally, carbon black has been widely used as an electrocatalyst support because of its high electronic conductivity, high surface area and cost effectiveness (7). However, carbon black exhibited several micropores (pores with $2 \mathrm{~nm}$ or less) for trapping the catalyst nanoparticles that are not accessible to methanol (8). This problem must be more pronounced with glucose. Hence, catalytic activity of metal loading carbon black decreases.

Marimo nano carbon (MNC) was investigated as a carbon material instead of carbon black for the catalyst support. $\mathrm{MNC}$ is a fibrous carbon material that comprises high-density spherical carbon nanofilaments (CNFs) $(9,10)$. CNFs were synthesized using oxidized diamond supported catalysts. The synthesized CNFs exhibit a cup-stack primary structure $(11,12)$. The edge of the graphene sheets was exposed to the CNF surface area. Pt nano particles can be supported on the edge of the CNF graphene sheets. Also, MNC have mesopores that (pores with 2-50 nm) allow ionic diffusion and rapid mass transfer. 
Already, Pt loaded MNC have been shown to be highly active for DMFC (Direct Methanol Fuel Cell) (13). The use of the MNC supported catalyst in DGFCs is assumed to be beneficial as it can improve catalytic activity and mass transfer.

In this study, we investigated the effect of pore size on DGFC Power generation performance by using three types of MNC with different pore sizes as catalyst supports for negative electrodes.

\section{Experimental}

$\underline{\text { Synthesis of MNC }}$

Oxidized diamond (O-dia: Diamond Innovations Corp.)-supported Ni catalysts were prepared by impregnating an aqueous solution of $\mathrm{Ni}\left(\mathrm{NO}_{3}\right)_{2} \cdot 6 \mathrm{H}_{2} \mathrm{O}$ (FUJIFILM Wako Pure Chemical Corp.) into the suspended oxidized diamond followed by evaporation-to-dryness. In this study, three kinds of catalysts with metal weight of 5, 10 and $15 \mathrm{wt} \%$ were prepared. MNC was synthesized using fluidized bed reactor, where the catalyst (Ni/O-dia: $0.3 \mathrm{~g}$ ) was spread on a gas distributor and introduced into a furnace. The reaction was performed for $30 \mathrm{~min}$ at $773 \mathrm{~K}$ with $\mathrm{C}_{2} \mathrm{H}_{4}(90 \mathrm{~mL} / \mathrm{min})$ as the carbon feed. The synthesized MNCs are expressed as MNC, MNC-10 and MNC-15.

\section{Electrocatalyst Preparation}

The marimo nano carbon-supported catalyst containing $5 \mathrm{wt} \% \mathrm{Pt}$ metal was prepared according to the modified nanocolloidal method. The projected Pt loading amount on the MNCs was $5 \mathrm{wt} \%$. First, MNC was added to deionized water, stirred under ultrasonication for $30 \mathrm{~min}$. Second, citric acid aqueous solution (FUJIFILM Wako Pure Chemical Corp.) and $\mathrm{H}_{2} \mathrm{PtCl}_{6} \cdot 6 \mathrm{H}_{2} \mathrm{O}$ aqueous solution (FUJIFILM Wako Pure Chemical Corp.) ware used as stabilizing agent and Pt precursor, respectively, were added to the MNC-added solution. Second the solution was stirred under ultrasonication for 30min. Finally, $\mathrm{NaBH}_{4}$ aqueous solution (FUJIFILM Wako Pure Chemical Corp.) as the reducing agent was added to the solution. After stirring under ultrasonication for 30min, the supernatant was removed from the solution by centrifugation and dried at $333 \mathrm{~K}$. For comparison, Vulcan XC-72 (Cabot Corp., VXC72IP) carbon black was also prepared under the same condition. The prepared Pt loading carbons are expressed as $\mathrm{Pt} / \mathrm{MNC}, \mathrm{Pt} / \mathrm{MNC}$ 10, Pt/MNC-15 and Pt/Vulcan, respectively.

\section{Characterization and Fuel cell test}

Surface structure of synthesized carbon nanofilaments were recorded by scanning electron microscopy (SEM, HITACHI S-4800). The specific surface area and porous characterization by $\mathrm{N}_{2}$ adsorption at $77 \mathrm{~K}$ using Belsorp Mini (Microtrac BEL Corp.). The BET equations were applied to determine the apparent surface area $\left(\mathrm{S}_{\mathrm{BET}}\right)$, and the BJH method was used to calculate the pore volume.

Membrane electrode assemblies (MEA) were subjected power generation performance of DGFC. The carbon-supported Pt catalyst, deionized water, and 5\% Nafion ${ }^{\circledR}$ dispersion solution (DuPont. DE521 CS type) were mixed under ultrasonication for preparing the catalyst ink. The prepared Pt loading carbons were used anode. MEA was

made by thermal transfer of the catalyst ink to Nafion membrane (Nafion117: The 
Chemours Corp.). The Pt loaded amount was $0.24 \mathrm{mg} \mathrm{cm}^{-2}$ for the anode and $0.48 \mathrm{mg} \mathrm{cm}^{-}$ 2 for cathode. The MEAs were fabricated by hot pressing at $433{ }^{\circ} \mathrm{C}$ at a pressure of $12 \mathrm{MPa}$ for $10 \mathrm{~min}$. The fuel cell performances were recorded at $353{ }^{\circ} \mathrm{C}$, and $0.3 \mathrm{M} \mathrm{C}_{6} \mathrm{H}_{12} \mathrm{O}_{6}$ aqueous solution $\left(0.5 \mathrm{~mL} \mathrm{~min}^{-1}\right)$ and air $\left(50 \mathrm{~mL} \mathrm{~min}^{-1}\right)$ were supplied to the anode and cathode, respectively.

\section{Results and Discussion}

Figure 1 shows SEM images of MNC, MNC-10, MNC-15 and Vulcan XC-72. MNCs synthesized consist of thin fibers and thick fibers and has three-dimensional interfiber voids. The larger the Ni loading amount on the O-dia, the thicker the fiber diameter of $\mathrm{CNF}$, and MNC-15 has the thickest fiber. Vulcan XC-72 was agglomeration of carbon fine particles.

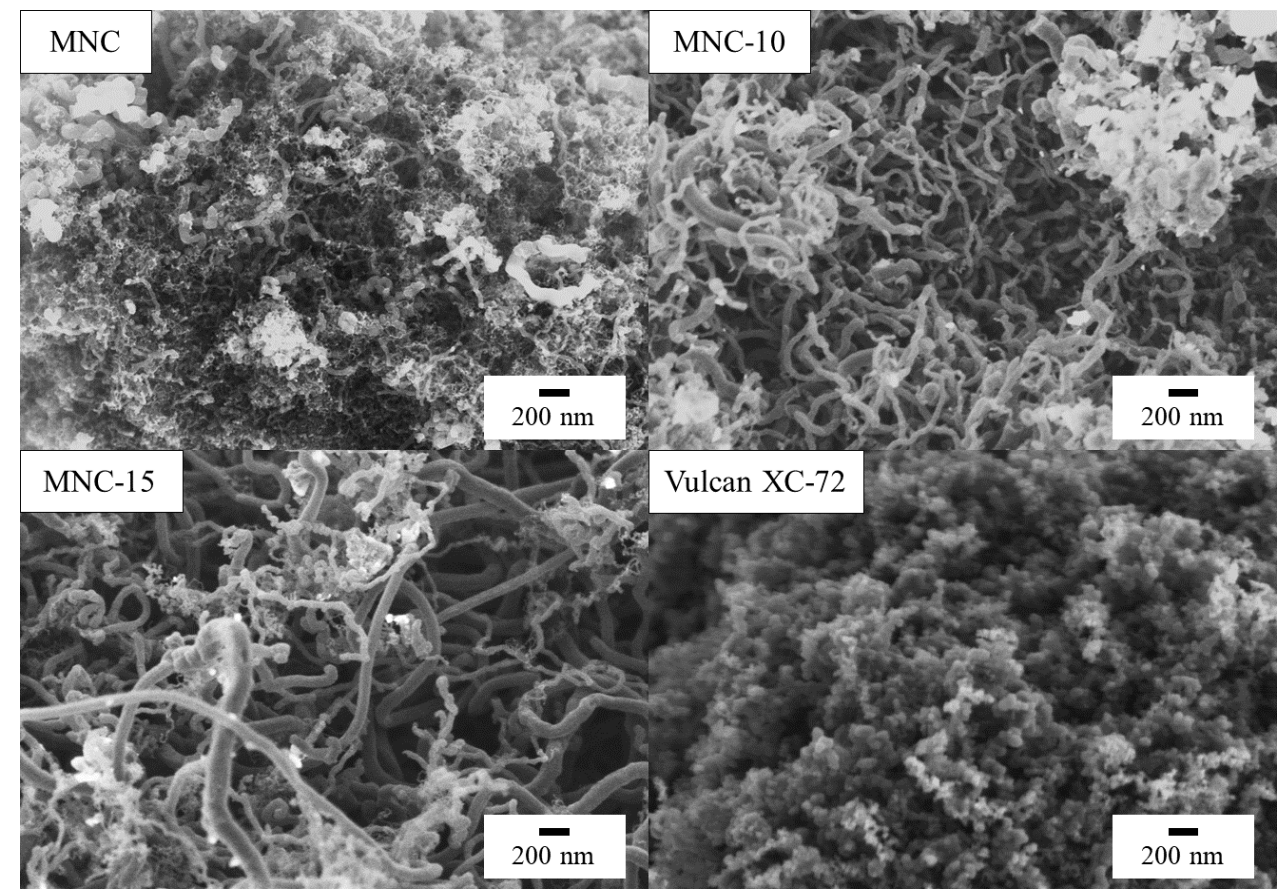

Figure 1. SEM images of MNC, MNC-10 and MNC-15.

TABLE I shows specific surface areas and Pore characteristics of carbon materials. Comparing the specific surface areas of the three types of MNCs synthesized, the larger the Ni loading amount on the O-dia, the lower the specific surface area. This is because the length of the fiber is shortened by increasing the Ni loading amount without changing the amount of synthesis gas. MNC, MNC-10 and MNC-15 had more mesopores than Vulcan. The larger the Ni loading amount, the larger the pore size. Therefore, MNC-15 had the largest pore sizes and the highest $\mathrm{V}_{\text {meso+macro }}$ (pore volume of 2-200 nm) in the synthesized MNCs. 
TABLE I. Specific surface areas and pore characteristics of carbon materials.

\begin{tabular}{cccccc}
\hline Catalysts & $\begin{array}{c}\mathbf{S}_{\text {BET }} \\
{\left[\mathbf{m}^{2} / \mathbf{g}\right]}\end{array}$ & $\begin{array}{c}\mathbf{V}_{\text {meso }} \\
{\left[\mathbf{c m}^{\mathbf{3}} / \mathbf{g}\right]}\end{array}$ & $\begin{array}{c}\mathbf{V}_{\text {macro(50-200 }} \\
{\left[\mathbf{c m}^{3} / \mathbf{g}\right]}\end{array}$ & $\begin{array}{c}\mathbf{V}_{\text {meso+macro }} \\
{\left[\mathbf{c m}^{\mathbf{3}} / \mathbf{g}\right]}\end{array}$ & $\begin{array}{c}\mathbf{d}_{\text {peak(vol) }} \\
{[\mathbf{n m}]}\end{array}$ \\
\hline MNC & 181 & 0.35 & 0.04 & 0.39 & 12.1 \\
MNC-10 & 153 & 0.45 & 0.11 & 0.56 & 18.4 \\
MNC-15 & 133 & 0.40 & 0.20 & 0.60 & 28.2 \\
Vulcan XC-72 & 236 & 0.20 & 1.08 & 1.21 & - \\
\hline
\end{tabular}

TABLE II shows maximum power densities using a single cell in combination with the four patterns. The maximum current densities of MEAs with Pt/ MNC, Pt/MNC-10, $\mathrm{Pt} / \mathrm{MNC}-15$ and Pt/Vulcan in anode were $0.33,0.58,0.72$ and $0.05 \mathrm{~mW} \mathrm{~cm}{ }^{-2}$, respectively. The power generation performance of a single cell using Pt/MNC-15 in anode was the best. Hence, utilizing MNC-15 as the catalyst support material in anode was more advantageous than the conventional carbon black. The low power generation performance of a single cell using Pt/Vulcan is assumed to be due to the fuel not reaching the Pt particles existing in the micropores of carbon black. There are reports that MNC supports Pt catalyst in a highly dispersed manner along the CNF edge (13). Therefore, the excellent power generation performance of $\mathrm{Pt} / \mathrm{MNC}-15$ is also due to the improvement of the catalyst utilization rate due to the high dispersion of Pt nano particles.

The maximum power density of a single cell using Pt/MNC-15 in anode was approximately 2.2 times that of a single cell using Pt/MNC in anode. Pore size of about 30 $\mathrm{nm}$ which MNC-15 has are considered to promote rapid mass transfer of reactants and products and ion diffusion. Therefore, further improvement in power generation performance can be expected by using nanocarbon materials with larger pores.

TABLE II. Maximum power densities for DGFC using $0.3 \mathrm{M} \mathrm{C}_{6} \mathrm{H}_{12} \mathrm{O}_{6}$ at $353 \mathrm{~K}$.

\begin{tabular}{cc} 
Catalysts & $\begin{array}{c}\text { Maximum Power density } \\
{\left[\mathrm{mW} / \mathrm{cm}^{2}\right]}\end{array}$ \\
\hline $\mathrm{Pt} / \mathrm{MNC}$ & 0.33 \\
$\mathrm{Pt} / \mathrm{MNC}-10$ & 0.58 \\
$\mathrm{Pt} / \mathrm{MNC}-15$ & 0.72 \\
$\mathrm{Pt} /$ Vulcan & 0.05 \\
\hline
\end{tabular}

\section{Conclusions}

In this study, an electrode catalyst support considerably affected the performance of the DMFCs. In Particularly, pore characteristic of carbon materials is important. For the $\mathrm{N}_{2}$ adsorption measurement, MNC-15 had larger pore size and higher pore volume compared to MNC and MNC-10. Pt/MNC-15 exhibited excellent performance as a glucose oxidation catalyst. Therefore, pores with a size of about $30 \mathrm{~nm}$ could improve fuel transport and improve DGFC power generation performance.

\section{Acknowledgment}

This work was supported by JSPS KAKENHI Great Number 20K12274. 


\section{References}

1. A. Zebda, L. Renaud, M. Cretin, C. Innocent, F. Pichot, R. Ferrigno and S. Tingry, Journal of Power Sources, 193 (2009) 602-606

2. T. miyake. M. Oike, S. Yoshino, Y. Yatagawa, K. Haneda, H, Kaji and M. Nishizawa, Chemical Physics Letters, 480 (2009) 123-126

3. M. Holzinger, A. L. Goff and S. Cosnier, Electrochemical Acta, 82 (2012) 179190

4. H. Sakai, T. Nakagawa, Y. Tokioka, T. Hatazawa, T. Ikeda, S. Tsujimura and K. Kano, Energy Environ. Sci., 2 (2009) 133-138

5. C.-H. Su, C.-L. Sun, S.-Y. Peng, J.-J. Wu, Y.-H. Huang and Y.-C. Liao, Journal of the Taiwan Institute of Chemical Engineers, 000 (2018) 1-7

6. D. Basu and S. Basu, INTERNATIONAL OF HYDROGEN ENERGY, 37 (2012) 4678-4684

7. H. Shioyama and K. Yasuda, TANSO, 2013 [No.210] 236-242

8. S. Sharma and B. G. Pollet, Journal of Power Sources, 208 (2012) 96-119

9. K. Nakagawa, H. Oda, A. Yamashita, M. Okamoto, Y. Sato, H. Gamo, M. Nishitani-Gamo, K. Ogawa and T. Ando, J Mater Sci., 44 (2009) 221-226

10. K. Nakagawa, M. Yamagishi, H. Nishimoto, N. Ikenaga, T. Kobayashi, M. Nishitani-Gamo, T. Suzuki and T. Ando, Chem. Mater., 15 (2003) 4571-4575

11. G. Tsujino, K. Nakagawa, H. Oda and T. Ando, Trans. Mat. Res. Soc. Japan, 38[3] (2013) 435-438

12. F. Tsujino, H. Ota, M. Nishitani-Gamo, K. Nakagawa and H. Oda, TANSO, 2015 [No.266] 2-6

13. K. Yutai, K. Saito, H. Oda, T. Ando, K. Nakagawa, Catalysis Letters, 149 (2019) $1-6$ 